\title{
POLÍTICAS DE AVALIAÇÃO EM LARGA ESCALA E INSTITUCIONAL: PERFIL DA PRODUÇÃO NA PÓS-GRADUAÇÃO
}

MARIA ANGÉLICA PEDRA MINHOTO

\section{RESUMO}

Este artigo apresenta análise da produção na área da política educacional, realizada em Programas de Pós-Graduação em Educação brasileiros, com foco na avaliação em larga escala e institucional. Foram examinados resumos de 81 teses e dissertações elaboradas no período de 2000 a 2010. Observou-se interesse crescente nessa temática, ainda que muito incipiente e disperso entre os programas de pós-graduação, as linhas de pesquisa e os orientadores. Foi constatada a inexistência de estudos comparados, tanto em nivel nacional como internacional, bem como grande concentração de estudos nas regiões Sudeste e Sul, reiterando a presença de diferenças na produção e distribuição de conhecimento na área da educação. Identificaram-se problemas na redação dos resumos, pela pouca objetividade e ausência de informações básicas. Poucos mencionam referenciais teóricos, indicando fragilidade na produção de conhecimento na área diante do vigor das políticas em avaliação educacional.

PALAVRAS-CHAVE AVALIAÇÃO EM LARGA ESCALA • AVALIAÇÃO INSTITUCIONAL • AVALIAÇÃO DA PÓS-GRADUAÇÃO • PRODUÇÃO TÉCNICO-CIENTÍFICA. 


\section{RESUMEN}

Este artículo presenta un análisis de la producción en el área de la política educacional, realizada en Programas brasileños de Postgrado en Educación, que enfocan la evaluación en larga escala e institucional. Se examinaron resúmenes de 81 tesis y disertaciones elaboradas en el periodo del 2000 al 2010. Se observó un creciente interés en dicha temática, aunque muy incipiente y disperso entre los programas de postgrado, las líneas de investigación y los tutores. Se constató la inexistencia de estudios comparados, tanto a nivel nacional como internacional, así como una gran concentración de estudios en las regiones Sudeste y Sur, reiterando la presencia de diferencias en la producción y distribución de conocimiento en el área de la educación. Se identificaron problemas en la redacción de los resúmenes, en función de la poca objetividad y ausencia de informaciones básicas. Pocos mencionan referentes teóricos, indicando fragilidad en la producción de conocimiento en el área frente al vigor de las políticas en evaluación educacional.

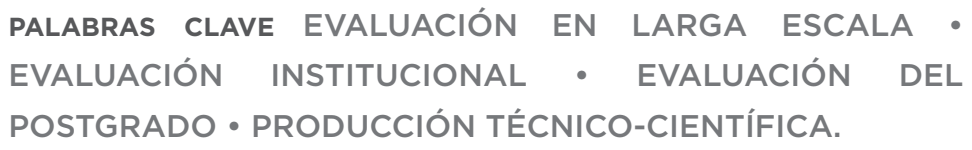

\section{ABSTRACT}

This article analyzes the production in the area of educational policies, conducted in Brazilian Graduate Programs in Education, focusing on largescale and institutional evaluation. Eighty-one theses and dissertations, developed during the period from 2000 to 2010 were examined. Growing interest in this topic was observed, although in the early stages and dispersed among the graduate programs, research lines and advisors. No comparative studies were found, either at the national or the international levels. In addition, a large concentration of studies in the southern and southeastern regions was found, reiterating the presence of differences in the production and distribution of knowledge in the area of education. Problems in the texts of the abstracts were identified regarding the scarce objectivity and lack of basic information. Few studies indicate theoretical references, showing weakness in the production of knowledge in the area in the face of the strength of educational evaluation policies.

KEY WORDS LARGE-SCALE EVALUATION • INSTITUTIONAL EVALUATION - GRADUATE PROGRAM - TECHNICAL-SCIENTIFIC PRODUCTION. 


\section{INTRODUÇÃO}

O objetivo deste artigo é apresentar resultados parciais de uma pesquisa interinstitucional, financiada pela Coordenação de Aperfeiçoamento de Pessoal de Nível Superior (Capes) e pelo Conselho Nacional de Desenvolvimento Científico e Tecnológico (CNPq). Produzida por docentes e estudantes de seis instituições públicas de ensino superior, situadas em cinco estados do país, a pesquisa teve como propósito descrever os principais traços da produção de conhecimento em política educacional, realizada em Programas de Pós-Graduação em Educação (PPGE) brasileiros. O grupo partiu do suposto de que revisões sistemáticas e frequentes do estado da arte em determinada área do conhecimento são fundamentais para o próprio desenvolvimento da área, pois permitem identificar as tendências da produção de forma representativa, manter relação com levantamentos anteriores e, portanto, avaliar o avanço na produção do saber, além de destacar os métodos e as referências teóricas mais utilizados, os objetos mais frequentes de interesse, bem como as lacunas da produção. Nesse sentido, um dos objetivos específicos da pesquisa foi o 
de caracterizar temas, problemas, procedimentos de método e regiões brasileiras estudadas que têm mobilizado a área da política educacional na pós-graduação brasileira.

Pondera-se, entretanto, que estudos caracterizados como estado da arte apresentam algumas limitações, ainda mais quando fundamentados em informações constantes tão somente de resumos dispostos em bancos de dados específicos, como é o presente caso, que tem como fonte primária o banco de teses da Capes. Além das normas estabelecidas pela agência, relativas à extensão, à forma e ao conteúdo desses pequenos textos, essa produção também padece em virtude da natureza textual e da qualidade do material encontrado, como se verá mais adiante. Por fim, tal como ocorre em qualquer operação analítica, destaca-se ainda que tal trabalho é subjetivamente permeado, visto que, em certa medida, as "lacunas, ambiguidades, singularidades [presentes nos resumos], são preenchidas pela leitura que o pesquisador faz" do material (FERREIRA, 2002, p. 269).

Para compor o corpus de análise, foram selecionadas todas as teses e dissertações produzidas no período de 2000 a 2010, no âmbito de PPGEs, com nota de avaliação Capes igual ou superior a cinco no triênio 2008-2010. Os programas selecionados estão nas seguintes instituições de ensino: Pontifícia Universidade Católica do Rio de Janeiro (PUC-RJ); Universidade Estadual do Rio de Janeiro (UERJ); Universidade Federal de Minas Gerais (UFMG); Pontifícia Universidade Católica do Rio Grande do Sul (PUC-RS); Universidade Federal Fluminense (UFF); Universidade do Vale dos Sinos (Unisinos); Universidade de São Paulo (USP); Pontifícia Universidade Católica de São Paulo (PUC-SP); Universidade Federal do Espírito Santo (Ufes); Universidade Federal de Goiás (UFG); Universidade Federal de Pelotas (UFPel); Universidade Federal do Paraná (UFPR); Universidade Federal do Rio Grande do Sul (UFRGS); Universidade Federal do Rio de Janeiro (UFRJ); Universidade Federal do Rio Grande do Norte (UFRN); Universidade Federal de São Carlos (UFSCar); Universidade Federal de Uberlândia (UFU); Universidade Estadual Paulista "Júlio de Mesquita Filho" (Unesp-Marília); Universidade Estadual de Campinas (Unicamp); e Universidade Metodista de Piracicaba (Unimep). 
1 Na divulgação inicial de resultados parciais da pesquisa em anais de eventos e em artigo publicado em revista indexada (2014), foi informado o total de 1.305 trabalhos, todavia durante revisão final, observou-se que 22 trabalhos computados foram apresentados em programa de pós-graduação de outras áreas que não a da educação, sendo, portanto, descartados

Nota-se que, entre essas instituições, cinco são confessionais, quatro são públicas estaduais e 11 são públicas federais, conferindo às instituições públicas a proporção de dois terços dos PPGEs mais bem avaliados no triênio, sendo o outro terço das confessionais. Quanto à localização, 13 instituições situam-se na região Sudeste, com seis no estado de São Paulo, quatro no do Rio de Janeiro, duas em Minas Gerais e uma no Espírito Santo; cinco na região Sul, sendo quatro no Rio Grande do Sul e uma no Paraná; uma no Nordeste, no Rio Grande do Norte, e uma no Centro-Oeste, em Goiás.

Em 2012, foi realizada coleta no banco de teses da Capes e levantados 1.283 trabalhos classificados pelos pesquisadores em nove eixos temáticos. ${ }^{1} \mathrm{~A}$ primeira fase da coleta de dados teve por base uma classificação prévia de temas descrita no projeto submetido às agências de fomento, em 2011. Ao longo do levantamento, os pesquisadores realizaram análise preliminar dos resumos e palavras-chave encontrados, com o objetivo de eliminar os estudos que não versavam sobre políticas educacionais, tomando como referência a distinção feita por Martins (1993) entre educação e política educacional, que entende a última como conjunto de propostas que dão organicidade ao processo de escolarização direcionado às instituições de ensino.

A análise revelou a inadequação dos parâmetros de busca e seleção, definidos inicialmente no projeto, o que levou o grupo a rever a classificação preliminar dos eixos e estabelecer outros parâmetros para definição de temas e palavras-chave. Como consequência, reiniciou-se a coleta no banco da Capes, atendendo aos novos parâmetros definidos, e só então foram selecionados e posteriormente organizados em nove eixos temáticos os 1.283 trabalhos. Os eixos são: organização, planejamento, administração e gestão da educação; avaliação em larga escala e avaliação institucional; qualidade da educação e do ensino; Estado e reformas educacionais, neoliberalismo na educação, terceiro setor e organizações sociais na educação, análise e avaliação de políticas educacionais; políticas de formação de professor e carreira docente; financiamento da educação e controle social do financiamento da educação; abordagens teórico-metodológicas 
em pesquisas sobre políticas educacionais; análise e avaliação de programas e projetos no campo educacional; e políticas inclusivas.

Em relação à forma de organização dos trabalhos, vale destacar a decisão do grupo de não classificá-los por níveis, etapas ou modalidades de ensino, mas por eixos temáticos, considerando a incidência, o alcance e a transversalidade das políticas educacionais sobre o sistema e as redes de ensino do país.

Neste artigo, o foco da análise está circunscrito ao eixo avaliação em larga escala e avaliação institucional, composto por um conjunto de 81 teses e dissertações, representando 6,2\% do total de estudos coletados. Além da observância em relação à procedência dos trabalhos aos PPGEs previamente definidos, as palavras-chave que balizaram a coleta e posteriormente contribuíram para a organização dos trabalhos nesse eixo foram as seguintes: política educacional; política educação; avaliação educacional; avaliação da educação; avaliação na educação; avaliação em educação; avaliação externa; avaliação institucional; avaliação em larga escala; avaliação de larga escala; exame nacional; Sistema Nacional de Avaliação da Educação Básica (Saeb); Prova Brasil; Provinha Brasil.

Dado que a avaliação é parte constitutiva dos processos de política pública e, portanto, tema recorrente das agendas de governo, bem como de interesse de pesquisas em nível de pós-graduação, é imprescindível evidenciar os critérios usados para o agrupamento dos trabalhos em torno do eixo avaliação em larga escala e avaliação institucional, em vista do material encontrado no sítio da Capes e também de sua organização nos vários eixos temáticos definidos no projeto, já que muitos agregam teses e dissertações consideradas pertencentes à grande área de avaliação em política educacional, porém com características e especificidades próprias.

Em relação ao grande campo da avaliação em políticas e educação, a análise permitiu observar aspectos similares na definição e constituição de objetos de estudos, o que tornou possível sua agregação. Inicialmente, notou-se a existência de focos distintos de avaliação em "políticas", "programas" e "projetos" educacionais. Tomou-se como base a conceituação de Rua (1997, p. 2), em que são definidos: 
Programa como um conjunto de ações e estratégias gerais que expressam os objetivos de uma determinada política, usualmente estruturados em um conjunto de projetos específicos; projetos - consistem numa ação planejada, estruturada em objetivos, resultados e atividades e desenvolvida num determinado local, com público alvo, tempo de duração e recursos limitados. Já as políticas públicas compreendem um conjunto de decisões e ações relativas à alocação imperativa de valores.

Tendo em vista tal definição, foram agregados no eixo análise e avaliação de programas e projetos no campo educacional os trabalhos cujos objetivos estavam primordialmente circunscritos à análise da eficácia e/ou eficiência e/ou efetividade e/ou impacto de programas ou projetos educacionais específicos, tais como o Programa Nacional de Integração da Educação Profissional com a Educação Básica na Modalidade de Educação de Jovens e Adultos (Proeja), a Escola de Tempo Integral, o Programa Brasil Alfabetizado, o Programa Universidade para Todos (ProUni), entre outros. Em relação aos trabalhos de avaliação classificados no eixo Estado e reformas educacionais, os estudos caracterizam-se pela análise de políticas educacionais amplas, que consideram os processos políticos que permeiam as agendas e propostas de governos, com a participação de vários sujeitos sociais, tais como a avaliação das reformas do ensino médio, da educação infantil, da educação de jovens e adultos; a apreciação da implementação de propostas curriculares, em diferentes estados e municípios; a expansão do ensino superior; etc.

Quanto ao eixo qualidade da educação e do ensino, os trabalhos arrolados agregam-se fundamentalmente em torno da análise do conceito de qualidade na educação e no ensino, ora versando sobre temas e problemas teóricos - como o sentido público da qualidade, o conceito de qualidade social da educação, a concepção de qualidade nas diferentes etapas, níveis e redes de ensino, o conceito de excelência em educação, os princípios do processo de acreditação de instituições, a definição de qualidade total em educação -, ora procedendo a análises de dados, como a relação entre a qualidade da 
educação e diferentes fatores que medeiam o processo de ensino e aprendizagem de alunos nas escolas e salas de aula, as práticas de ensino e gestão, o currículo, a composição de turmas, etc. Em suma, o tema central desses estudos é a busca pela conceituação da qualidade da educação e do ensino, sob diferentes plataformas de análise.

Há também nos eixos políticas de formação de professor e carreira docente, financiamento da educação e políticas inclusivas teses e dissertações que, em certa medida, analisam e avaliam políticas, programas e projetos específicos das referidas áreas temáticas. Entretanto, quando considerada a distinção entre o tema principal e o tema secundário dos trabalhos, definiu-se pela classificação nos eixos mencionados.

Em relação ao eixo avaliação em larga escala e avaliação institucional, os estudos foram agregados em torno do propósito de analisar iniciativas de aferição externa e padronizada do rendimento escolar, nos diferentes níveis e etapas de ensino, relacionadas a estudos de contexto, e realizadas sob a responsabilidade dos governos estaduais, municipais ou federal, ainda que sejam iniciativas distintas, que apresentam população-alvo, abrangência geográfica, metodologias e propósitos específicos, tais como Saeb, Exame Nacional do Ensino Médio (Enem), Sistema de Avaliação de Rendimento Escolar do Estado de São Paulo (Saresp), Exame Nacional de Desempenho de Estudantes (Enade), entre outras. Foram agregados também a esse eixo os trabalhos que tiveram como propósito o estudo de iniciativas específicas de autoavaliação em instituições de ensino, em vista de seus processos de organização, gestão e funcionamento, bem como de seus resultados em relação a metas previamente estabelecidas, em geral levadas a cabo por vários segmentos da comunidade escolar. Além disso, foram igualmente reunidos no eixo os estudos que buscaram analisar a articulação desses processos de avaliação, teórica e praticamente.

Tendo sido feitos os esclarecimentos e as distinções iniciais, o presente artigo desdobra-se em mais três partes. A seguir, discute-se a estruturação do campo da política de avaliação em larga escala e de avaliação institucional, no Brasil. Posteriormente, são apresentados os resultados da pesquisa, 
em relação ao eixo temático em tela, de forma agregada, isto é, tecendo considerações gerais, sem distinção específica sobre os diferentes focos de avaliação presentes no eixo, com o intuito de evidenciar tendências e lacunas. Por fim, são tecidas algumas considerações sobre os dados apresentados, indicando novas possibilidades e necessidades para a área.

\section{AVALIAÇÃo EM LARGA ESCALA E AVALIAÇÃO INSTITUCIONAL NO BRASIL}

As iniciativas de avaliação em larga escala, subordinadas a políticas de aferição do desempenho de sistemas e redes de ensino, são recentes no país, datando do final da década de 1980, com a realização do Sistema Nacional de Avaliação do Ensino Público de $1^{\circ}$ grau (Saep), precursor do atual Saeb (BONAMINO; FRANCO, 1999). A justificativa para a realização dessa iniciativa foi a necessidade de se aprofundar o entendimento sobre o baixo desempenho dos estudantes brasileiros em escolas públicas, até então monitorado pelas taxas de repetência e evasão escolar e pelo índice de conclusão ao final das diferentes etapas da educação básica. Além disso, havia o propósito de auxiliar na definição de novas formas de intervenção educacional, voltadas para a alteração do quadro preponderante do que se tem convencionalmente chamado de "fracasso escolar". Bonamino e Franco (1999), ao estudarem o processo de institucionalização do Saeb, recuperam os questionamentos de alguns intelectuais brasileiros que, no final da década de 1980 e início dos anos 1990, colocam em xeque as metodologias de apuração das estatísticas oficiais, provocando a adoção de novos modelos de diagnóstico e modificações nos procedimentos estatísticos do Ministério da Educação (MEC).

Vale lembrar que a centralidade dos debates sobre o desempenho dos estudantes entre os educadores, após 30 anos de ditadura militar, teve por base a defesa do direito à educação, da gestão democrática nas escolas e da necessidade de reorganização do ensino básico no sentido de tornar possível a formação para o exercício pleno da cidadania, com amplo acesso aos conhecimentos socialmente valorizados. No final dos anos 1980, o objetivo dessa primeira iniciativa de avaliação externa foi, portanto, levantar dados sobre o desempenho dos 
estudantes, em diferentes áreas do saber e etapas de ensino, para mapear suas dificuldades e conhecer os fatores a ele associados. Os resultados dessa avaliação consolidaram a urgência da implementação de uma política abrangente de avaliação externa para a educação nacional (WAISELFISZ, 1991).

Em 1996, com a promulgação da Lei de Diretrizes e Bases da Educação Nacional (LDB) (Lei n. 9394/96), foram oficializados os procedimentos de avaliação externa, com o objetivo de induzir e cobrar dos sistemas de ensino um padrão mínimo de qualidade (art. $9^{\circ}$ ). À União ficou determinado que assegurasse um

[...] processo nacional de avaliação do rendimento escolar no ensino fundamental, médio e superior, em colaboração com os sistemas de ensino, objetivando a definição de prioridades e a melhoria da qualidade do ensino. (BRASIL, 1996, art. 9º)

Cury (1998), ao analisar as perspectivas e mudanças subjacentes à LDB, identifica uma tendência regressiva em relação à histórica luta da sociedade civil organizada pela consolidação de um sistema nacional de educação. Nas palavras do autor, o espírito da LDB "vai da negação de um sistema nacional de educação à afirmação de um sistema nacional de avaliação" (CURY, 1998, p. 76).

De lá para cá, tem sido possível notar a multiplicação de iniciativas de avaliação externa, no Brasil, propostas pelas diferentes esferas da administração pública, bem como para os diferentes níveis de ensino (LOPES, 2007; BONAMINO; BESSA; FRANCO, 2004; MINHOTO, 2013). De forma concomitante, o governo federal passa a adotar uma política de terceirização de inúmeros serviços públicos, tendo inclusive instituído um ministério, entre 1995 e 1998 (Mare), ${ }^{2}$ cujo objetivo era o de reformar e "modernizar" as atividades exercidas pelo governo, de modo que sua função não mais se caracterizasse pela execução, mas sim pela gestão e avaliação dos serviços públicos, passando de uma administração burocrática a uma administração gerencial (PEREIRA, 1996).

Segundo Dias Sobrinho (2002, p. 46),

[...] a avaliação assumiu basicamente as características de accountability: ${ }^{3}$ uma forma tecnocrática de valorar e um
2 Ministério da Administração Federal e Reforma do Estado.

3 Termo em inglês sem tradução exata para o português, que se refere, na administração pública, à criação de mecanismos de controle burocrático que visam tornar efetiva a responsabilidade de servidores públicos, bem como prestar contas em relação às suas ações. Termo polissêmico, tem ampliado, nas últimas décadas, seu escopo e sentido, como se pode observar no estudo de Mulgan (2000), ao mostrar que, para além do senso comum de "prestar contas", accountability tem sido usado para conceituar aspectos internos à conduta pública, relacionados às instituições que controlam tal conduta, aos meios para que o funcionalismo se comprometa com os interesses públicos e ao diálogo democrático entre os cidadãos, o que amplia a definição de Dias Sobrinho (2002). 
procedimento burocrático de exigir o cumprimento de obrigações. É inevitável a conexão entre a accountability e a ideologia da eficiência.

Nota-se que, no atual "ramo" das avaliações em larga escala, a elaboração e operacionalização das iniciativas também foram terceirizadas e passaram a ser capitaneadas por profissionais cuja formação pouco ou nada se relaciona à área da educação. Vê-se instalar entre os governos a demanda por serviços de avaliação que exigem conhecimentos técnicos específicos, contribuindo para a formação de um mercado de avaliação educacional amplamente mediado pela lógica dos negócios (MINHOTO, 2008).

Pode-se afirmar, também, que é recente a instalação de políticas sistêmicas de avaliação institucional no Brasil. Os complexos procedimentos relativos à autoavaliação das instituições de ensino ainda precisam ser efetivamente incorporados, a despeito da indução operada pelos governos tanto no ensino superior quanto na educação básica. No ensino superior, tal indução tornou-se evidente no início da década de 1990, quando o governo federal estabeleceu o Programa de Avaliação Institucional das Universidades Brasileiras (Paiub). Essa iniciativa teve como fundamento a autoavaliação, conduzida pelas próprias instituições, no sentido de qualificar, de forma ampla, as diversas dimensões da vida acadêmica, respeitando a autonomia universitária e institucional, sendo sua adesão voluntária, sem caráter punitivo ou de premiação como consequência dos resultados obtidos (MINHOTO, 2013).

Entretanto, o Paiub foi paulatinamente esvaziado, a partir de meados dos anos 1990, em vista da implementação do Exame Nacional de Curso (ENC), vulgarmente conhecido como "Provão", que passou a privilegiar exclusivamente a aferição do desempenho dos estudantes, deixando de contemplar os meandros estruturais que fazem parte do cotidiano das instituições (DIAS SOBRINHO, 2002). Mais recentemente, em 2004, por pressão das instituições superiores de ensino, o governo federal aboliu o ENC e instituiu o Sistema Nacional de Avaliação da Educação Superior (Sinaes), que, em contraste com a política anterior, voltou seu foco também à avaliação institucional. 
Em relação à educação básica, políticas sistêmicas de avaliação institucional começaram a ganhar maior visibilidade a partir dos anos 2000. Em geral, trata-se de programas conduzidos por governos estaduais e municipais, responsáveis pela oferta desse nível educacional, sendo em alguns casos apoiados por organizações da sociedade civil. Algumas iniciativas em diferentes estados e municípios ocorrem na rede estadual do Ceará, a partir de 2000; em Igrejinha (RS), em 2002; na rede estadual do Paraná, em 2004; em Suzano (SP), em 2006; em Campinas (SP), em 2007; em Amparo (SP), em 2010; no Rio Grande do Sul, em 2012; em Cuiabá (MT), em 2013; em Blumenau (SC), em 2014; entre outros. ${ }^{4}$ Também é possível verificar a indução de iniciativas mais sistemáticas de avaliação institucional, nos estados e municípios, por meio de programas de capacitação para gestores da educação básica, como é o caso do Programa de Capacitação a Distância para Gestores Escolares (Progestão), existente desde o final da década de $1990,{ }^{5}$ e da utilização de materiais de ampla difusão pública, como os "Indicadores da Qualidade na Educação" (Indique).

De acordo com Ribeiro e Gusmão (2010), o Indique foi publicado em 2004 e organizado pela Ação Educativa - uma associação civil sem fins lucrativos, fundada em São Paulo em 1994 -, em conjunto com o Fundo das Nações Unidas para a Infância (Unicef), o Programa da Nações Unidas para o Desenvolvimento (Pnud), o Instituto Nacional de Estudos e Pesquisa Educacionais (Inep) e o MEC. Com base na legislação educacional brasileira e em discussões com várias entidades do setor, entre elas a União Nacional dos Dirigentes Municipais de Educação (Undime) e o Consed, o material consiste em

[...] uma proposta metodológica participativa e em um sistema de indicadores por meio dos quais a comunidade avalia a situação de diferentes aspectos da escola, identifica prioridades, estabelece um plano de ação e implementa e monitora ações voltadas à qualidade na educação. (RIBEIRO; GUSMÃO, 2010, p. 825)

No sítio eletrônico da Ação Educativa é possível acessar estudo que relata a abrangência do uso do Indique como instrumento de avaliação institucional em nove secretarias de
4 Para mais informações, ver: <http://imagens.seplag.ce.gov.br/ PDF/20000217/do20000217p01. pdf>; <http://download.inep.gov.br/ outras_acoes/laboratorio/banco_de experiencias/avaliacao_e_resultados_ educacionais/2006/IgrejinhaRS06. pdf>; <http://www.gestaoescolar. diaadia.pr.gov.br/modules/conteudo/ conteudo.php?conteudo=95>; <http:// www.campinas.sp.gov.br/governo/ educacao/depto-pedagogico/ avaliacao-institucional/index.php>; <http://www.educacao.rs.gov.br/ $\mathrm{pse} / \mathrm{html} /$ seap.jsp?ACAO=acaol>; <http://www.cuiaba.mt.gov.br/ secretarias/educacao/avaliacaoinstitucional-apresenta-resultado-deanalise-do-ppp-das-escolas/4545>; $<$ http://www.blumenau.sc.gov.br/ secretarias/secretaria-de-educacao/ semed/educacao-prepara-avaliacaoinstitucional-da-rede-municipal-deensino $48>$.

5 ○ Progestão foi desenvolvido pelo Conselho Nacional de Secretários de Educação (Consed) em parceria com diversas secretarias estaduais e municipais de educação, desde o final da década de 1990, e oferece um módulo específico de avaliação institucional. Para mais informações, ver: <http://www.rededosaber.sp.gov. br/portais/Default.aspx?tabid=645>. Acesso em: 28 out. 2010. 
6 ostudo está disponível em <http://www.acaoeducativa.org. br/index.php/component/content/ article/54-institucional/1512 indicadores-da-qualidade-naeducacao-balanco-de-resultados> Acesso em: 28 out. 2014

educação situadas em diferentes regiões do Brasil: secretarias estaduais do Amazonas, da Bahia e do Rio de Janeiro e secretarias municipais de Guarulhos (SP), Ibitiara (BA), Ituiutaba (MG), Londrina (PR), São Felix (BA) e Suzano (SP). ${ }^{6}$

O pouco tempo de existência dessas iniciativas parece contribuir para explicar a baixa frequência da produção de pesquisas em nível de pós-graduação na área, ainda que se reconheça, desde meados da década de 1980, no campo educacional, a necessidade de avaliações de monitoramento de sistemas e instituições de ensino em todo o país.

\section{PESQUISAS SOBRE POLÍTICA EM AVALIAÇÃO EDUCACIONAL: CARACTERÍSTICAS GERAIS}

Neste item, alguns traços dos trabalhos selecionados na pesquisa e categorizados no eixo avaliação em larga escala e avaliação institucional serão analisados, a fim de se delinearem as características que têm configurado o campo, ao longo do período 2000-2010. Para tanto, foram conduzidas análises comparativas, principalmente em face de um recente trabalho organizado por Bauer e Reis (2013) sobre a produção teórica em avaliação de sistemas educacionais no Brasil, no período de 1988 a 2011, dada a similaridade em relação ao objeto deste estudo e à metodologia adotada, visto que as autoras também mapearam a produção acadêmica, por meio do estudo de teses e dissertações, selecionando igualmente os resumos dos trabalhos no Banco de Teses da Capes.7

As informações contidas no banco de dados desta pesquisa foram sistematizadas com o objetivo de informar as principais características dos trabalhos produzidos no período 2000-2010 sobre a temática da avaliação em larga escala e avaliação institucional nos programas de pós-graduação que compõem a pesquisa. Dos 81 trabalhos selecionados, 50 são dissertações e 31 são teses, em uma proporção de 0,62 trabalhos de mestrado e 0,38 de doutorado. Durante o período em tela, é possível afirmar que a produção se intensificou recentemente, visto que mais de $60 \%$ dos trabalhos foram defendidos nos últimos quatro anos (2007-2010), com destaque para 2010. Prevaleceram o maior número e o crescimento das dissertações, sendo que em 2001, 2002 e 2006 não houve 
produção de teses sobre a temática. Entretanto, também nos últimos quatro anos da série, foi possível notar tendência positiva para a produção de teses, tendo os anos de 2005 e 2007 apresentado número maior de teses do que de dissertações. Esse crescimento indica tendência já observada por Macedo e Sousa (2010) ao estudarem o estado da arte da pesquisa em educação no Brasil. As autoras afirmam que

[...] como vem ocorrendo desde 1965, a produção de dissertações e teses cresceu ao longo do último triênio. A maior parte dela ainda se dá em instituições federais, especialmente no que concerne aos cursos de doutorado. (MACEDO; SOUSA, 2010, p. 168)

GRÁFICO 1: Número de titulados, segundo nível e ano da defesa

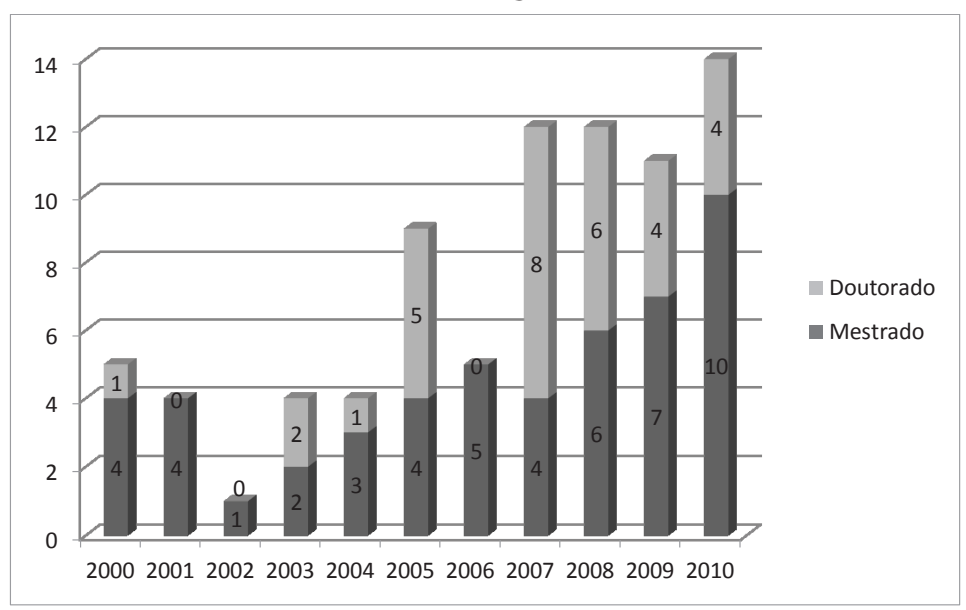

Fonte: Banco de dados da pesquisa interinstitucional. (Gráfico elaborado pela autora).

De forma semelhante, a pesquisa organizada por Bauer e Reis (2013) analisou a produção da área entre 1988 e 2011 e selecionou 294 trabalhos, assim distribuídos: $78,2 \%$ de dissertações de mestrado; $15 \%$ de teses de doutorado; e 6,8\% de mestrados profissionalizantes. Com uma amostra muito superior à desta pesquisa, seja pelo recorte temporal (que foi de 24 anos de produção, em vista dos 11 anos analisados neste estudo), seja pela quantidade de programas de pós-graduação (71 programas), não são só restritos à área da educação, em 76 diferentes instituições (em vista dos 17 PPGEs 
selecionados por esta pesquisa), pode-se notar a prevalência ainda maior da produção em nível de mestrado.

Além disso, sobre as características da distribuição temporal dos estudos, as autoras mostram que as primeiras iniciativas de avaliação de sistemas, apesar de terem ocorrido no final dos anos 1980 e início dos 1990, passaram a ser foco de estudos na pós-graduação apenas em fins de 1990. A produção se intensificou nos anos 2000, atingindo seu auge em 2010 - exatamente o mesmo pico identificado na amostra aqui analisada -, mas primordialmente em nível de mestrado, já que a produção de teses é pontual, tendo sido a primeira defendida em 1999, segundo as autoras.

É preciso considerar, no entanto, que o grande número de cursos de mestrado aumenta a possibilidade de acesso dos estudantes a esse nível da pós-graduação e sua titulação que é, em termos de frequência, muito superior à frequência de doutorado, conforme se observa no Gráfico 2, extraído do sítio da Capes.

GRÁFICO 2: Distribuição de titulados, segundo nível, no período de 1998 a 2012

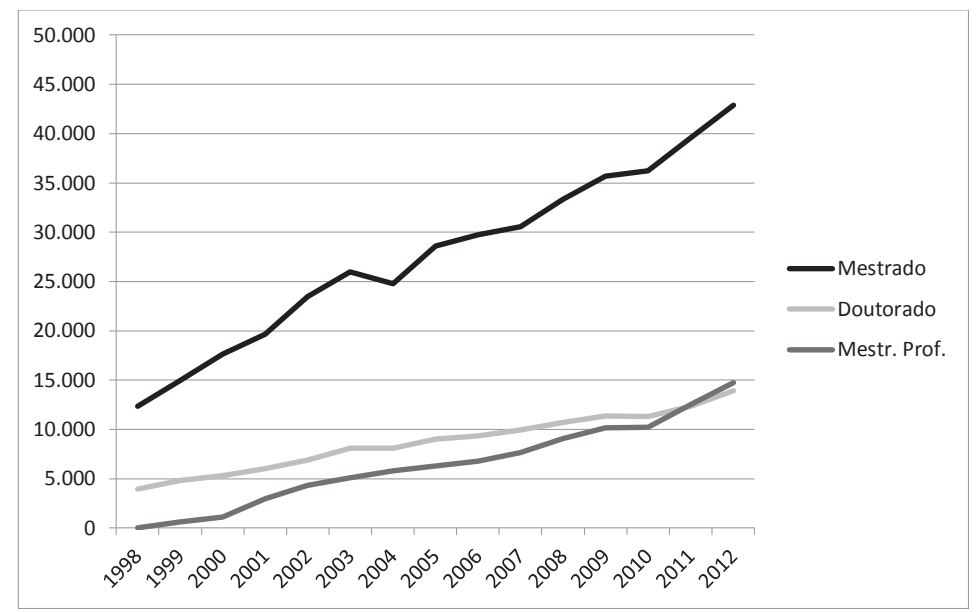

Fonte: Base de dados Geocapes (BRASIL, 2012). Disponível em: <http://geocapes.capes.gov.br/>. Acesso em: 28 out. 2014. (Gráfico elaborado pela autora).

O número total de titulados da série histórica referente ao período 1998-2012, presente no sítio da Capes, distribui-se, por nível, em 72,2\% de mestres, $22,8 \%$ de doutores e 5,1\% de mestres profissionais. Nota-se que o comportamento dos 
balanços realizados sobre a produção na temática varia em relação aos dados gerais da Capes. O estudo aqui apresentado, que tomou por base os PPGEs mais bem avaliados no triênio 2008-2010, revela uma produção de teses que se apresenta em maior proporção (38\%) do que o balanço realizado por Bauer e Reis (2013) em um universo muito mais abrangente, cuja proporção de teses é de 15\%. Esses dados reforçam ainda mais as conclusões de Macedo e Sousa (2010), no que concerne às características da produção em nível de doutorado, em geral fortemente estabelecida em instituições públicas de ensino.

Dos 17 PPGEs que atenderam aos critérios desta pesquisa, todos apresentaram ao menos duas produções sobre a temática, no período, sendo que cinco programas tiveram apenas dissertações (Ufes, UFRN, Unimep, UERJ e UFPR), um apenas teses (UFRGS) e um com mais teses do que dissertações (Unisinos), conforme evidenciado no Gráfico 3.

GRÁFICO 3: Número de titulados, segundo o nível e instituição

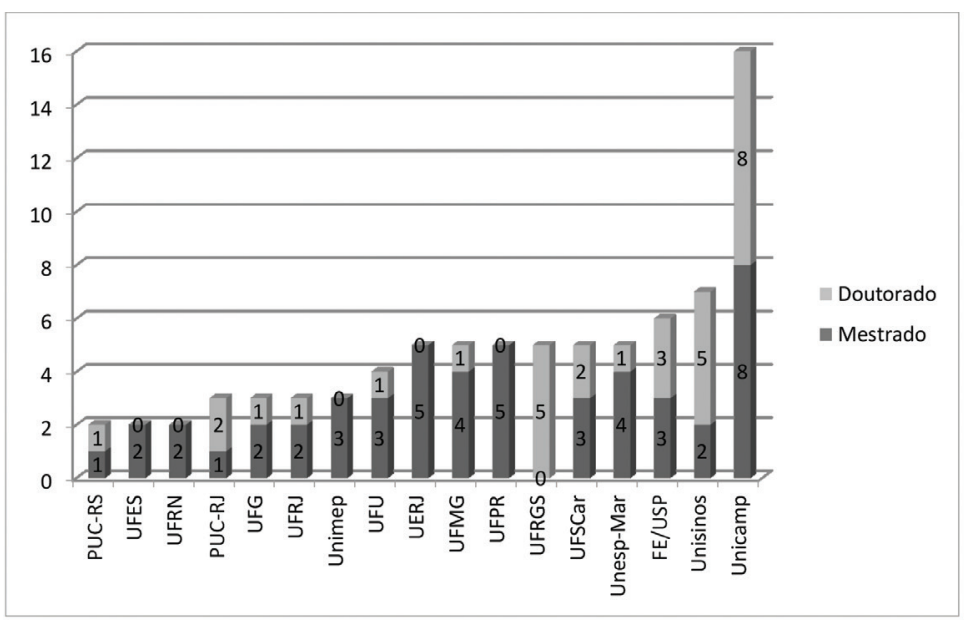

Fonte: Banco de dados da pesquisa interinstitucional. (Gráfico elaborado pela autora).

Destaca-se a ampla produção da Unicamp sobre o tema, com oito teses e oito dissertações, representando $20 \%$ do total de trabalhos classificados no eixo temático. Vale destacar que, entre as 1.283 teses e dissertações que compõem o banco de dados desta pesquisa sobre política educacional, a Unicamp aparece com 15\% da produção, ou seja, 197 trabalhos no total. 
A diferença dessas proporções obtidas pela Unicamp - 20\%, no eixo em análise, e 15\% sobre o total dos trabalhos coletados - confirma que seu PPGE vem de fato contribuindo bastante para a produção do conhecimento na área. No estudo de Bauer e Reis (2013), a maior parte da produção também está localizada em instituições públicas (65\%), com destaque para as universidades federais $(41,2 \%)$ e estaduais $(23,5 \%)$, responsáveis igualmente por parte significativa da produção em nível de doutorado. Não foi possível verificar no estudo das autoras qual instituição se destaca na produção acadêmica sobre a temática.

Em relação aos orientadores, notou-se que 55 docentes foram responsáveis por levar à defesa 81 estudantes, entre mestres e doutores. Dentre os que se destacam com mais orientações estão: Sandra Maria Zákia Lian Sousa, da USP, com cinco orientações; Denise Balarine Cavalheiro Leite, da UFRGS, e Luiz Carlos de Freitas, da Unicamp, com quatro orientações cada; Francisco Creso Junqueira Franco Jr., da PUC-RJ; Maria Amelia Sabbag Zainko, da UFPR; José Dias Sobrinho, José Roberto Rus Perez e Mara Regina Lemes de Sordi, da Unicamp, com três orientações cada. Nota-se que todos os orientadores aqui mencionados são também autores de referência em vários trabalhos produzidos tanto no âmbito da pós-graduação, em especial sobre o tema da avaliação, como em produções divulgadas em revistas indexadas.

Dos 55 orientadores arrolados no eixo temático, apenas oito são responsáveis por $35 \%$ das orientações realizadas, sendo que quatro deles estão credenciados em uma mesma instituição de ensino, a Unicamp, fato que revela a constituição de uma identidade institucional (e de seu PPGE) em relação a essa área específica de conhecimento. Em outras instituições, por sua vez, essa identidade ainda não se caracterizou de forma explícita, seja pela baixa concentração de orientações por docentes, seja pela enorme dispersão nos temas de orientação, não configurando, portanto, o foco específico que caracteriza a pesquisa naquele programa.

Bauer e Reis (2013, p. 13) identificam 217 diferentes orientadores para os 294 trabalhos da amostra, o que dá em média 1,3 trabalho por orientador, uma dispersão relativamente superior 
à encontrada nesta pesquisa, que foi de 1,5 trabalho por orientador. As autoras destacam que, entre os orientadores, apenas 38 foram responsáveis pela orientação de mais de uma produção e que 15 deles concentraram 23,5\% da orientação das teses e dissertações, tendência similar à encontrada nesta pesquisa. Em relação à inserção profissional desses docentes, eles estão distribuídos nas seguintes instituições: Universidade de Brasília (UnB), Universidade Federal de Juiz de Fora (UFJF), UFRJ, PUC-RJ, PUC-SP, Faculdade de Educação da Universidade de São Paulo (FE/USP), Universidade Federal da Bahia (UFBA), Unisinos, Faculdade de Economia, Administração e Contabilidade da Universidade de São Paulo (FEA/USP), Faculdade de Economia, Administração e Contabilidade de Ribeirão Preto da Universidade de São Paulo (FEA-RP/USP), Universidade Federal Rural de Pernambuco (UFRPE), Unesp-Marília, Fundação Cesgranrio e Universidade Federal de Minas Gerais (UFMG).

Distintamente do que foi aqui verificado, a Unicamp não apareceu com o mesmo relevo na pesquisa de Bauer e Reis (2013), ainda que, dos 16 trabalhos produzidos na Unicamp catalogados no eixo avaliação em larga escala e avaliação institucional, 12 tenham como tema central diferentes iniciativas de avaliação externa na educação básica e no ensino superior.

As autoras verificaram que, entre os 294 autores das teses e dissertações, apenas dez deram continuidade à temática da avaliação de sistemas educacionais no mestrado e no doutorado. No caso desta pesquisa, apenas um dos 80 diferentes autores seguiu na temática nos PPGEs analisados.

Explorando ainda os aspectos gerais dos 81 trabalhos aqui arrolados, foi possível identificar uma relação de 40 linhas de pesquisa nas quais declararam vínculo os 81 mestres e doutores, o que de pronto parece revelar alta dispersão e baixa produção das linhas. Entre as linhas que se destacam com maior número de produções estão: "formação do professor, currículo e ensino superior" e "planejamento educacional, políticas e gestão educacional”, da Unicamp, cada uma com seis trabalhos vinculados; "Estado, sociedade e educação", da FE/USP; "políticas de formação, políticas e gestão da educação”, da UFRGS; e "política educacional, administração de sistemas educativos e unidades escolares”, da Unesp-Marília, cada uma 
com cinco trabalhos vinculados. Se, por um lado, essas cinco linhas concentram um terço da produção do eixo temático (27 trabalhos, em 12,5\% das linhas arroladas no eixo), revelando tendência de agregação da produção, por outro, há quase o mesmo número de trabalhos (25) vinculados solitariamente a uma linha de pesquisa, isto é, em 62,5\% das linhas há apenas a produção de um único trabalho classificado no eixo temático, no período, o que evidencia enorme dispersão e baixa produção em termos de linha de pesquisa no tema.

Sobre as linhas de pesquisa, Bauer e Reis (2013) apontam que as mais destacadas compreendem avaliação educacional (teoria e metodologia), currículo, política e gestão educacional e didáticas ou metodologias específicas de ensino, ligeiramente diferente do que foi aqui encontrado, uma vez que não se notou nos PPGEs selecionados qualquer linha de pesquisa que mencionasse explicitamente em sua denominação a avaliação educacional e as didáticas ou metodologias específicas de ensino.

Se considerarmos que o principal propósito da pós-graduação stricto sensu é a formação de novos quadros para a pesquisa e de professores, que, em geral, irão atuar no ensino superior, uma das preocupações preponderantes deveria ser o fortalecimento das linhas de pesquisa, com o vínculo explícito da produção de docentes e discentes. Em geral, bons programas de pós-graduação estão alicerçados em linhas de pesquisa produtivas, do que derivam projetos desenvolvidos por seus pesquisadores (professores e estudantes), exprimindo com isso a relevância de sua produção científica e o consequente reconhecimento da área na Capes. Entretanto, como revela Borges-Andrade (2003, p. 160), em geral, as linhas de pesquisa têm sido:

\footnotetext{
[...] transformadas em formas de organizar uma apresentação ou rótulos, ao invés de descreverem programas estabelecidos ou grupos de pessoas qualificadas e conjuntos de atividades estruturados que levariam à consecução de um fim justificado. É bastante provável, além disso, que tais linhas de pesquisa, numa quantidade bastante significativa de casos, nunca tenham passado por instâncias de discussão e aprovação institucionais.
} 
Nesta pesquisa, nota-se que a Unicamp é a instituição que mais se destaca na constituição de uma identidade na área específica de conhecimento. Contudo, cabe informar que o número de linhas de pesquisa registrado na Capes pode não refletir o número real de linhas presentes nos programas, tendo em vista a constatação de algumas incompatibilidades entre os dados coletados no banco de teses da Capes e o verificado nos sites das universidades envolvidas. ${ }^{8}$ No caso da Unicamp, por exemplo, observaram-se diferenças entre a denominação e número de linhas de pesquisa levantadas no banco de teses e os dados fornecidos pelo endereço eletrônico da universidade: das cinco linhas de pesquisa presentes no banco da Capes, somente "políticas públicas e educação" é citada na página eletrônica da Faculdade de Educação da Unicamp. O que se pretende aqui com esse alerta é chamar a atenção sobre alguns problemas detectados no banco de teses durante a realização da pesquisa, tendo em vista que se configura como principal fonte de informações sobre a produção da pós-graduação brasileira.

A seguir, apresentam-se os dados sobre a distribuição dos trabalhos segundo o país estudado:

TABELA 1: Número de trabalhos por país estudado

\begin{tabular}{l|c:c}
\hline PAÍs & NÚMERO & PORCENTAGEM \\
\hline Argentina, Brasil, Chile, México & 1 & 1,2 \\
\hline Brasil & 78 & 96,3 \\
\hline Brasil, Argentina & 1 & 1,2 \\
\hline Brasil, Portugal & 1 & 1,2 \\
\hline Total & 81 & 100,0 \\
\hline Fonte: Banco de dados da pesquisa interinstitucional. (Tabela elaborada pela autora).
\end{tabular}

No que se refere ao país estudado, nota-se, na Tabela 1, que os trabalhos se voltaram eminentemente à realidade brasileira. A totalidade dos resumos de teses e dissertações selecionadas para o eixo temático menciona o Brasil como lócus de pesquisa. Os estudos comparados somam a diminuta quantia de três trabalhos, que representa $4 \%$ sobre o total do eixo, mas ainda maior do que a proporção encontrada no âmbito de todas as teses e dissertações que compõem o
8 Pesquisa realizada nos sites dos programas em 23/10/2013. 
banco de dados da pesquisa sobre política educacional: são 29 estudos comparados em 1.283 , o que representa $2,2 \%$. Esse dado mostra o baixíssimo interesse e investimento dos pós-graduandos e de seus PPGEs em pesquisas sobre a política educacional comparada e, como tendência, revela a quase inexistência de iniciativas de intercâmbio internacional. Um maior interesse pelo quadro internacional das políticas educacionais favoreceria a delimitação mais consistente do campo, no país, ao identificar propósitos comuns e peculiaridades, em realidades e processos políticos distintos, e proporcionar meios para tensionar a suposta identidade entre políticas educacionais e questões eminentemente domésticas, dando contornos específicos às características das políticas brasileiras.

No que toca à temática circunscrita ao eixo, é de se estranhar o baixo interesse por estudos comparados, visto que as iniciativas de avaliação externa e avaliação institucional estão presentes em vários países de todos os continentes do globo, sendo induzidas por agências de financiamento internacional (como Banco Mundial, Banco Interamericano de Desenvolvimento, Banco Internacional para Reconstrução e Desenvolvimento), que monitoram e cobram o retorno de seus investimentos e o gerenciamento eficaz dos recursos disponíveis para a educação via indicadores de qualidade dos serviços educacionais, que utilizam testes padronizados censitários ou amostrais de desempenho de alunos, além de serem também induzidas ou adotadas por organizações internacionais (Organização para a Cooperação e o Desenvolvimento Econômico - OCDE -, Internacional Association for the Evaluation of Educational Achievement - IEA -, Laboratorio Latinoamericano de Evaluación de la Calidad de la Educación - LLECE - da Organização das Nações Unidas para a Educação, a Ciência e a Cultura - Unesco), como é o caso do Programa Internacional de Avaliação de Estudantes (Pisa), do Third Internacional Mathematics and Science Study (TIMSS), entre outros.

A avaliação de sistemas é hoje, sem sombra de dúvida, um mecanismo central de monitoramento das políticas educacionais para os governos de diferentes países, na medida 
em que permite "gerenciar à distância" a execução de objetivos previamente definidos, com alto grau de detalhamento das atividades educativas desenvolvidas nas escolas, mas estabelecidas em instâncias superiores, e posteriormente cobradas dos sistemas, via indicadores de desempenho, eficiência, eficácia, efetividade e impacto.

Além disso, nota-se que, no eixo temático, os estudos incidiram apenas sobre 11 estados e o Distrito Federal, não tendo sido encontrados trabalhos sobre o Acre, Alagoas, Amapá, Amazonas, Bahia, Ceará, Maranhão, Mato Grosso do Sul, Pará, Paraíba, Pernambuco, Rondônia, Roraima, Sergipe e Tocantins. Destaca-se a concentração de teses e dissertações nos estados do Sudeste (São Paulo, Rio de Janeiro, Minas Gerais e Espírito Santo), com 32 trabalhos (40\%), sendo apenas um deles comparativo (SP, RJ e MG), e mais da metade revela interesse nas iniciativas do estado de São Paulo. Em seguida, nota-se certa concentração nos estados do Sul (Rio Grande do Sul, Paraná e Santa Catarina), com 11 trabalhos (14\%). Ambas as regiões sendo objeto de estudo de mais de $50 \%$ dos trabalhos do eixo. Em relação a esses dados, não há como desconsiderar a alta concentração de programas de pós-graduação no Sudeste e Sul em detrimento das demais regiões (SOUSA; BIANCHETTI, 2007). Ou seja, permanece inalterada a falta de investimento dos programas em estudos comparativos - quer internacionais, como mostrado anteriormente, quer entre regiões do país -, bem como a falta de investimento em estudos sobre as regiões Norte, Nordeste e Centro-Oeste, tornando evidente a diferença na produção e distribuição do conhecimento em nosso país. Bauer e Reis $(2013$, p. 6) identificam que são também as avaliações externas presentes no Sul e Sudeste que têm sido foco sistemático das pesquisas, sendo que tal fenômeno ocorre pela concentração de grupos de pesquisa sobre avaliação e gestão educacional existentes nas universidades dessas regiões.

Outro dado relevante para esta pesquisa é a falta de informação em resumos de nove trabalhos do eixo (11\%), mostrando certa fragilidade na informação de um dos elementos básicos referentes às pesquisas realizadas. Os resumos devem sumarizar a pesquisa e, como é de conhecimento geral, no 
ambiente científico são o meio mais utilizado para a indexação, divulgação e acesso aos estudos. Os interessados consultam os resumos a fim de verificar se vale a pena realizarem a leitura completa da pesquisa para as finalidades que têm em vista. Por isso, os resumos devem ser claros, objetivos e descrever aspectos essenciais, tais como tema, problema, hipóteses, objetivos, procedimentos de método e de análise, referências teóricas, resultados e conclusões da investigação.

Em geral, as disciplinas de metodologia científica - invariavelmente presentes nos programas de pós-graduação brasileiros - apontam exaustivamente para a importância dessa questão. Para análise da qualidade dos resumos dos trabalhos coletados nesta pesquisa, foi feita uma classificação com os seguintes critérios:

- resumo completo - evidencia com clareza a problemática do estudo, os objetivos, a estratégia metodológica, a base teórica e os resultados alcançados;

- resumo parcialmente completo - mostra com clareza no mínimo três critérios relacionados ao resumo completo;

- resumo incompleto - evidencia menos de três itens do resumo completo;

- resumo superficial - não evidencia com clareza a problemática do estudo, os objetivos, a estratégia metodológica, a base teórica e os resultados alcançados, tornando difícil a compreensão dos propósitos da pesquisa.

De acordo com os parâmetros estabelecidos, cerca de $20 \%$ dos resumos foram considerados completos, $16 \%$ classificaram-se como incompletos e superficiais e $64 \%$ estavam parcialmente completos. Na revisão feita por Bauer e Reis (2013), em que foram considerados quatro elementos básicos como padrão mínimo esperado para o resumo (definição do objeto da pesquisa, metodologia utilizada, resultados e considerações finais), as autoras também notaram que muitos resumos não contemplavam as características mínimas para o gênero textual, sendo que $65 \%$ estavam incompletos, $1 \%$ não contemplou nenhum dos elementos básicos e $34 \%$ foram classificados 
como completos. Ainda que com critérios distintos, ambas as revisões apontam para a baixa observância às normas básicas de elaboração de resumos e, portanto, a necessidade de maior atenção por parte dos pesquisadores, dado que se trata de fator essencial para colocar a produção científica brasileira na área em condições de almejar reconhecimento e visibilidade, tanto interna como internacionalmente.

Em relação aos procedimentos de método, nota-se que 12 trabalhos (15\%) não informam qualquer procedimento, outra falha grave na elaboração dos resumos. Entre as 69 teses e dissertações que indicaram procedimentos metodológicos, muitas mencionam mais de um, revelando, ao que parece, atenção aos métodos e ao rigor científico e intenção de cruzamento de dados. Foram mencionados: a análise documental (39 trabalhos - 48\%); a entrevista (36 trabalhos - 44\%); o questionário (17 trabalhos - 21\%); a observação (11 trabalhos - 14\%); a revisão bibliográfica (nove trabalhos - 11\%); a análise estatística (oito trabalhos - 10\%); o grupo focal (sete trabalhos - 8\%); a análise de conteúdo (seis trabalhos - 7\%); o estudo de caso (quatro trabalhos - 5\%); e, com apenas uma menção, análise da aplicação da provinha Brasil; análise do Enem; diário de campo; enquete com caráter exploratório; levantamento de dados quantitativos; levantamento de dados qualitativos; memória; pesquisa de campo; testes de desempenho; e visitas à escola, uma situação que revela alta quantidade e dispersão de procedimentos.

Entretanto, um dos itens menos presentes nos resumos foi a indicação da referência teórica, ausente em dois terços das produções arroladas no eixo, ou seja, 54 trabalhos. Bauer e Reis (2013) encontram situação similar, porém mais extrema, informando que em $80,8 \%$ dos resumos não foram identificados referenciais teóricos e que, quando aparecem, a tendência é a citação de fontes de pesquisa ou "autores utilizados na construção do quadro teórico e não referenciais teóricos no sentido mais amplo" (BAUER; REIS, 2013, p. 16).

Verificado em ambas as pesquisas, esse fenômeno, aliado à constatação de que $85 \%$ dos trabalhos aqui analisados e $55,5 \%$ dos levantados por Bauer e Reis (2013) realizam descrição de procedimentos de coleta de dados, sugere a existência 
de certo pragmatismo dos estudos e possível fragilidade teórica para as análises empreendidas no campo da avaliação em educação. Nesta pesquisa, os traços marcantes encontrados na leitura dos resumos são a descrição de procedimentos de método e a indicação de relatos da prática, do cotidiano e de documentos. Essa possível dissociação entre dado empírico e análise teórica para elaboração do conhecimento na área, perceptível com a leitura apenas de resumos, sugere a hipótese, ainda a ser comprovada pela leitura integral das teses e dissertações arroladas neste estudo, de que fatos observados podem estar sendo concebidos como verdades.

O pensamento e a produção do conhecimento em ciências humanas e sociais não deveriam se deter diante da sistematização de dados levantados, mas sim operar sua análise por meio de conceitos teóricos, referidos à sociedade, revelando inclusive o que parece estar em oposição à própria manifestação empírica do objeto. A teoria deveria ser o meio pelo qual os dados ganhariam relevância, o meio de desvelar sua aparência e mostrar a conexão com as grandes tendências e processos sociais, dando sentido aos fenômenos observados.

Sobre as bases teóricas mencionadas, pode-se identificar, tal como fazem Bauer e Reis (2013), a "confusão" do que é destacado como referência nos resumos, visto que muitos trabalhos de naturezas semelhantes aos das teses e dissertações são referidos como bases teóricas. Sem qualquer intenção de passar em revista as inúmeras vertentes e tradições do pensamento social e seus diferentes entendimentos do conceito de teoria social, pode-se tomar como base para a compreensão dos propósitos da teoria o quadro das questões de que trata:

[...] o status das ciências sociais, especialmente em relação

à lógica das ciências naturais; a natureza das leis ou generalizações que podem ser estabelecidas; a interpretação da ação humana, bem como sua diferenciação dos objetos e eventos da natureza, finalmente, o caráter ou forma das instituições sociais. (GUIDDENS; TURNER, 1999, p. 7)

Em vista da amplitude e profundidade do trabalho intelectual envolvido na formulação de uma teoria social, é possível considerar que muitos dos trabalhos apontados nos 
resumos referem-se mais a fontes e resultados específicos de pesquisadores da área, o que deveria ser tomado como uma revisão bibliográfica extensiva, na medida em que permitem compilar fundamentos teóricos e metodológicos relevantes para o campo, do que propriamente a teóricos que formularam conceitos que possibilitam elucidar as determinações dos fenômenos sociais, não explícitas imediatamente.

Um último comentário a respeito das "bases teóricas" refere-se à menção, como referência teórica, em um dos resumos, de um documento produzido por um órgão oficial, situação que, além de confundir fonte de análise com referencial teórico, parece mostrar a subordinação da pesquisa acadêmica à agenda das políticas públicas do país e, mais preocupante ainda, a adesão irrefletida à referida agenda, faltando o distanciamento necessário para uma análise crítica das políticas educacionais brasileiras.

Por fim, analisam-se as palavras-chave, que têm o papel de identificar de maneira muito objetiva e direta os temas e assuntos centrais que são objetos de análise nas pesquisas, descritores que representam o conteúdo do documento ao qual se referem. As palavras-chave desempenham uma função complementar à do resumo, na medida em que oferecem uma espécie de estrato do texto, identificando os elementos cruciais da pesquisa, sendo que sua escolha pressupõe uma análise conceitual, com a identificação dos assuntos presentes no documento, e uma espécie de tradução, uma conversão da análise conceitual em determinado conjunto de termos (GONÇALVES, 2008, p. 5). Além disso, elas mostram o enfoque dado pelo autor nas discussões e geram identidades, situando o trabalho em determinada área do conhecimento, filtrando previamente, de certa forma, os leitores interessados no texto.

A Tabela 2 traz as palavras-chave que foram mencionadas por no mínimo dois trabalhos, além da frequência de palavras que foram mencionadas por apenas um trabalho. As primeiras estão organizadas em seis agrupamentos temáticos para propiciar um quadro racional de palavras-chaves mencionadas no eixo. 
TABELA 2: Frequência de palavras-chave

\begin{tabular}{|c|c|c|c|}
\hline AGRUPAMENTO & PALAVRAS-CHAVE & FREQUÊNCIA & PERCENTUAL \\
\hline $\begin{array}{l}\text { Avaliação e } \\
\text { educação }\end{array}$ & $\begin{array}{l}\text { Avaliação; avaliação educacional; avaliação em educação; avaliação } \\
\text { escolar; avaliação em larga escala; avaliação externa; Enem; Saresp; } \\
\text { avaliação da aprendizagem; Enade; Exame Nacional }\end{array}$ & 47 & 16,8 \\
\hline $\begin{array}{l}\text { Política, reforma } \\
\text { e Estado }\end{array}$ & $\begin{array}{l}\text { Política educacional; política e educação; política de educação; } \\
\text { políticas públicas; avaliação das políticas/programas educacionais; } \\
\text { avaliação de pesquisa; educação; educação e Estado; reforma do } \\
\text { ensino/educacional; Estado avaliador }\end{array}$ & 45 & 16,1 \\
\hline $\begin{array}{l}\text { Etapas e níveis } \\
\text { de ensino }\end{array}$ & $\begin{array}{l}\text { Ensino superior; educação superior; universidade e faculdade; } \\
\text { educação básica; ensino fundamental; educação profissional; escola } \\
\text { pública }\end{array}$ & 31 & 11,1 \\
\hline $\begin{array}{l}\text { Avaliação } \\
\text { institucional }\end{array}$ & Avaliação institucional; Paiub; projeto político pedagógico & 30 & 10,7 \\
\hline $\begin{array}{l}\text { Gestão e } \\
\text { qualidade }\end{array}$ & $\begin{array}{l}\text { Gestão educacional; gestão da escola; gestão da educação; } \\
\text { participação; escolas - organização e administração; gestão } \\
\text { democrática; Ideb; qualidade; qualidade da educação; qualidade do } \\
\text { ensino; qualidade educacional }\end{array}$ & 22 & 7,9 \\
\hline \multirow{3}{*}{ Genérico } & Educação matemática; Minas Gerais; prática pedagógica & 6 & 2,1 \\
\hline & Palavras mencionadas uma única vez & 99 & 35,3 \\
\hline & Total & 280 & 100,0 \\
\hline
\end{tabular}

Fonte: Banco de dados da pesquisa interinstitucional. (Tabela elaborada pela autora).

As palavras-chave foram compiladas em categorias, dada a falta de padrão ou norma para a sua escolha e redação, mostrando muitas vezes que os pesquisadores têm formas distintas de compreender e relacionar conceitos em vista dos fenômenos estudados. A categorização permitiu perceber, no entanto, algum nível de relacionamento entre elas quanto à representação do campo e à possibilidade de recuperação de informações, em acordo com o grande tema da política educacional e o eixo em análise, ainda que se verifique um percentual relativamente baixo de palavras-chave nos agrupamentos específicos de avaliação e de políticas somados não chegam a $50 \%$. As palavras-chave genéricas e aquelas mencionadas por apenas um trabalho podem, no entanto, indicar a tentativa dos pesquisadores de atribuir maior especificidade à própria produção, ampliando a gama de campos de inserção e auxiliando os interessados a encontrarem a produção. Bauer e Reis (2013) também organizaram as palavras-chave em categorias, obtendo o seguinte resultado: avaliação educacional (78); ensino e aprendizagem (41); 
formação de professores (13); métodos e técnicas de análise (30); planejamento, gestão e administração educacional (43); política educacional (156); e genéricas (89). As autoras apontam que muitas palavras-chave utilizadas são genéricas demais, atrapalhando a compreensão mais acurada da natureza dos trabalhos. Além disso, elas descrevem problemas de registro de palavras-chave no sítio da Capes, como o baixo número (menos de três de palavras-chave), palavras sem sentido ou incompletas e divergências das palavras encontradas na Capes e nos trabalhos.

\section{ALGUMAS CONSIDERAÇÕES FINAIS SOBRE AS POSSIBILIDADES E AS NECESSIDADES DA ÁREA}

O estudo da produção científica sobre o eixo avaliação em larga escala e avaliação institucional mostrou haver interesse crescente sobre a temática, ainda que muito incipiente, visto que representou apenas $6,2 \%$ da produção em política educacional compilada pelo grupo de pesquisa. Essa situação deve-se ao fato de ser um campo relativamente novo, em função do tempo de existência das iniciativas sistemáticas de avaliação em larga escala (início da década de 1990) e de avaliação institucional (início dos anos 2000), da inexistência de linhas de pesquisa específicas para o estudo dessas políticas e da dispersão da pesquisa sobre a temática entre os diferentes PPGEs, linhas de pesquisa e orientadores.

Na produção, foi possível identificar problemas na elaboração de vários resumos, que muitas vezes são longos, pouco objetivos e sem informações básicas sobre as pesquisas. Para cumprirem seu propósito de mostrar o estrato do trabalho científico realizado, sua elaboração precisa ganhar mais atenção dos autores, orientadores e PPGEs, fundamentalmente no trabalho das disciplinas de metodologia de pesquisa, devendo ser também avaliados com maior rigor quando das bancas examinadoras das teses e dissertações. Toda a comunidade científica deve se responsabilizar por isso. Outra lacuna extremamente preocupante foi a ausência de menção aos referenciais teóricos, em muitos resumos, o que é um indício, a ser devidamente indagado, de que se pode estar produzindo uma visão estreita, acrítica e frágil 
diante do desenvolvimento vigoroso e hegemonia das políticas de avaliação educacional, como anteriormente exposto. Os docentes e orientadores dos PPGEs também precisam atentar para essa questão, visto que o avanço da ciência, com a produção de novos conhecimentos, e a formação de jovens pesquisadores são justamente os principais propósitos dos programas de pós-graduação stricto sensu.

A inexistência de estudos comparados, tanto em nível nacional como internacional, coloca-se como um grande desafio para a área, bem como a superação da concentração dos estudos sobre as iniciativas nas regiões Sudeste e Sul do Brasil, reiterando a já conhecida desigualdade da produção e distribuição de conhecimentos. Por fim, é necessário o fortalecimento das linhas de pesquisa, no que toca à consistência teórica e à definição da direção e dos limites de interesse no campo de conhecimento, dando mais lógica e fundamento à produção sobre a temática.

\section{REFERÊNCIAS}

BAUER, A.; REIS, A. T. Balanço da produção teórica sobre avaliação de sistemas educacionais no Brasil: 1988 a 2011. In: REUNIÃO NACIONAL DA ANPED, 36., Goiânia-GO, 29 de setembro a 2 de outubro de 2013. Disponível em: <http://36reuniao.anped.org.br/pdfs_trabalhos_aprovados/gt05_ trabalhos_pdfs/gt05_3375_texto.pdf>. Acesso em: 19 jul. 2014.

BORGES-ANDRADE, J. E. Em busca do conceito de linha de pesquisa. Revista de Administração Contemporânea, Curitiba, v. 7, n. 2, jun. 2003. Disponível em: <http://www.scielo.br/scielo.php?script=sci_arttext\&pid=S141565552003000200009\&lng=en\&nrm=iso>. Acesso em: 28 out. 2014.

BONAMINO, A.; FRANCO, C. Avaliação e política educacional: o processo de institucionalização do SAEB. Cadernos de Pesquisa, São Paulo, n. 108, p. 101-132, 1999.

BONAMINO, A.; BESSA, N.; FRANCO, C. (Org.). Avaliação da educação básica. Rio de Janeiro: Loyola, 2004.

BRASIL. Coordenação de Aperfeiçoamento de Pessoal de Nível Superior. Geocapes dados estatísticos. 2012. Disponível em: < http://geocapes.capes.gov.br/ geocapesds/\#app $=$ c501\&da7a-selectedIndex $=0 \& 5317$-selectedIndex $=0 \& d b c b-$ selectedIndex=0>. Acesso em: 28 out. 2014.

BRASIL. Presidência da República. Casa Civil. Lei n. 9.394, de 20 de dezembro de 1996 - Lei de Diretrizes e Bases da Educação. Brasília, DF, 1996. 
CURY, C. R. J. Lei de Diretrizes e Bases e perspectivas da educação nacional. Revista Brasileira de Educação, Rio de Janeiro, n. 8, ago. 1998. Disponível em: <http://educa.fcc.org.br/scielo.php?script=sci arttext\&pid=S1413-24781998000200007\&lng=pt\&nrm=iso>. Acesso em: 28 out. 2014.

DIAS SOBRINHO, J. Universidade e avaliação: entre a ética e o mercado. Florianópolis: Insular, 2002.

FERREIRA, N. S. de A. As pesquisas denominadas "Estado da Arte”. Educação \& Sociedade, Campinas, v. 23, n. 79, p. 257-272, ago. 2002. Disponível em: $<$ http://www.scielo.br/pdf/es/v23n79/10857.pdf>. Acesso em: 15 jul. 2015.

GONÇALVES, A. L. Uso de resumos e palavras-chave em ciências sociais: uma avaliação. Encontros Bibli: Revista Eletrônica de Biblioteconomia e Ciência da Informação, Florianópolis, n. 26, jul./dez. 2008.

GUIDDENS, A.; TURNER, J. H. Teoria social hoje. Tradução de Gilson C. C. de Sousa. São Paulo: Editora Unesp, 1999.

LOPES, V. V. Cartografia da avaliação educacional no Brasil. 2007. Tese (Doutorado em Educação) - Faculdade de Educação, Universidade de São Paulo, São Paulo, 2007.

MACEDO, E.; SOUSA, C. P. de. A pesquisa em educação no Brasil. Revista Brasileira de Educação, Rio de Janeiro, v. 15, n. 43, jan./abr. 2010.

MARTINS, C. Política educacional. São Paulo: Brasiliense, 1993.

MINHOTO, M. A. P. Política de avaliação da educação brasileira: limites e perspectivas. In: SOUZA, A. R.; GOUVEIA, A. B.; TAVARES, T. M. (Org.). Políticas educacionais: conceitos e debates. 2. ed. Curitiba: Appris, 2013. v. 1, p. 1-216.

Da disseminação da cultura de avaliação educacional: estudo sobre a institucionalização do Enem. Poiésis: Revista do Programa de Pós-Graduação em Educação, Tubarão, SC, v. 1, p. 67-85, 2008.

MULGAN, R. Accountability: an ever-expanding concept? Public Administration, v. 78, n. 3, p. 555-573, 2000. Disponível em: <https://crawford.anu.edu.au/pdf/ staff/richard_mulgan/MulganR_02.pdf>. Acesso em: 16 nov. 2013.

PEREIRA, L. C. B. Da administração pública burocrática à gerencial. Revista do Serviço Público, Brasília, v. 47, n. 1, jan./abr. 1996.

RIBEIRO, V. M.; GUSMÃO, J. B. B. de. Uma leitura dos usos dos indicadores da qualidade na educação. Cadernos de Pesquisa, São Paulo, v. 40, n. 141, p. 823-847, set./dez. 2010. Disponível em: <http://www.scielo.br/scielo. php?script=sci_arttext\&pid=S0100-15742010000300008\&lng=en\&nrm=iso $>$. Acesso em: 28 out. 2014.

RUA, M. das G. Análise de políticas públicas: conceitos básicos. Brasília, DF: Programa de Apoio a Gerência Social no Brasil, BID, 1997. 
SOUSA, S. S.; BIANCHETTI, L. Pós-graduação e pesquisa em educação no Brasil: o protagonismo da ANPEd. Revista Brasileira de Educação, Rio de Janeiro, v. 12, n. 36, p. 389-546, set./dez. 2007.

WAISELFISZ, J. O sistema nacional de avaliação do ensino público de $1^{\circ}$ grau. Estudos em Avaliação Educacional, São Paulo, n. 4, p. 65-72, jul./dez. 1991.

\section{MARIA ANGÉLICA PEDRA MINHOTO}

Professora doutora do Departamento de Educação da Escola de Filosofia, Letras e Ciências Humanas e pró-reitora de graduação da Universidade Federal de São Paulo (EFLCH/ Unifesp), São Paulo, São Paulo, Brasil

mminhoto@unifesp.br 
